better than $80 \%$, even while the rest of the New Deal came under increasing attack. He talked of "a plan of cooperation with nature instead of what we have been doing in the past - trying to buck nature". This was an appeal for cooperation among the people too.

Maher uses the CCC to make a sophisticated argument within the field of environmental history in the United States. He argues, in effect, that it is the missing link between the simple conservation of the Theodore Roosevelt era (1901-09) and the environmentalism that emerged after the Second World War. The link was forged by Franklin D. Roosevelt's 'broader conservation', which went beyond concern for efficiently managing natural resources to include people and communities in a more ecological form of national planning.

Just as important for Maher's argument were the grassroots reactions to the CCC. Planting trees seemed to be all for the good until early conservation biologists began to worry about how wildlife habitats were being changed. Meanwhile, the CCC's mania for blazing trails and building roads inspired a movement to preserve roadless wilderness areas. Maher argues for a bottom-up view of this new deal for nature, effectively turning the significance of the original New Deal (an undeniably topdown enterprise) on its head.

If the New Deal is going to be a touchstone for our economy and environment today, our inspiration should go further than the CCC. Maher leans too heavily on this one agency to explain the enormous changes that took place during the Depression and in its aftermath. One fundamental problem here is making a virtue of necessity. The CCC, like the rest of the New Deal, was tightly constrained by American politics, which was (still is) enamoured with the idea of bottom-up change, and thus wary of economic and environmental planning on a national scale.

Maher briefly opens up a view on this larger context in a chapter on the CCC's work with the Tennessee Valley Authority, a massive regional development programme undertaken by the national government. He does not follow the story into the authority's hydroelectric dams and energy. It is there, in the nexus of energy and environment, that we might find the real lessons of the New Deal for our troubled times. Unfortunately, it was not so much the New Deal as the Second World War that ultimately transformed the economy of the United States. Arguably, the war also transformed the country's relationship with the environment more than the CCC did. But that is another story. One can only hope that particular history does not have to be repeated for the United States to resolve another new deal for nature in this current era of global change.

Jon Christensen is associate director of the

Spatial History Project in the Bill Lane Center for the Study of the North American West at Stanford University, California 94305-4225, USA.

\section{Bedtime reading}

Insomniac

by Gayle Green

University of California Press: 2008.

520 pp. $\$ 29.95$

\section{Jim Horne}

Californian professor Gayle Green has been an insomniac for 50 years. For her, insomnia has been an ordeal of suffering and anger, directed largely at medical professionals, sleep clinics and the providers of various potions, pills and other sleep aids. In spite of this, her informed insider's account of insomnia is a testament to how well we can apparently survive on far less than eight hours of sleep per night.

Although her inability to function is a message Green may want to convey, being a professor of literature we must allow her some poetic licence. After pouring out her woes, and pointing out that rats die without sleep and that insomnia may lead to all manner of ills, the book settles down to an interesting read. Green gives a fair reflection of how difficult life can be for insomniacs. Focusing on the United States, she interviews insomnia experts, tries out every conceivable sleep treatment and attends learned conferences on sleep disorders. Albeit from a personal viewpoint, she provides home truths and insights that many sleep researchers and doctors have lost track of; they would benefit from reading this book.

Claiming not to be depressed, obsessive or hypochondriacal, Green believes she has a genetic form of insomnia that leads to 'physiological hyperarousal' with additional hormonal underpinnings. For her, it is a physical condition and not 'all in the mind'. In my mind lingers the thought that "the lady doth protest too much". Make of the author what you will, Insomniac is among the best books of its kind. Besides, there are millions of people just like her, seemingly beyond the bounds of modern medicine.

Insomnia is one of the few disorders that a general practitioner will allow a patient to self-diagnose. The patient may be rewarded with a short course of hypnotic drugs; but even the best of these medicines is unlikely to lengthen night sleep by more than 20 minutes, usually by quickening sleep onset by the same amount. This is not enough to improve daytime alertness, mainly because many sufferers are hyperaroused and constantly 'on the go' - that's why they can't sleep. Others, such as Green, report being tired all the time, which is different from sleepiness and the propensity to fall asleep.

This tiredness can be linked to insomnia, but both are usually symptoms of something more deep-seated. Treating the insomnia alone (by hypnotic drugs, for example) makes little difference and can be an expensive, frustrating and fruitless course of action, especially in the United States, where sleep induction is a billion-dollar industry. Many, like Green, then seek the solace and sympathies of alternative therapies.

Insomnia comes in many forms: difficulty in falling asleep, too many fitful awakenings or waking up too early. Although there

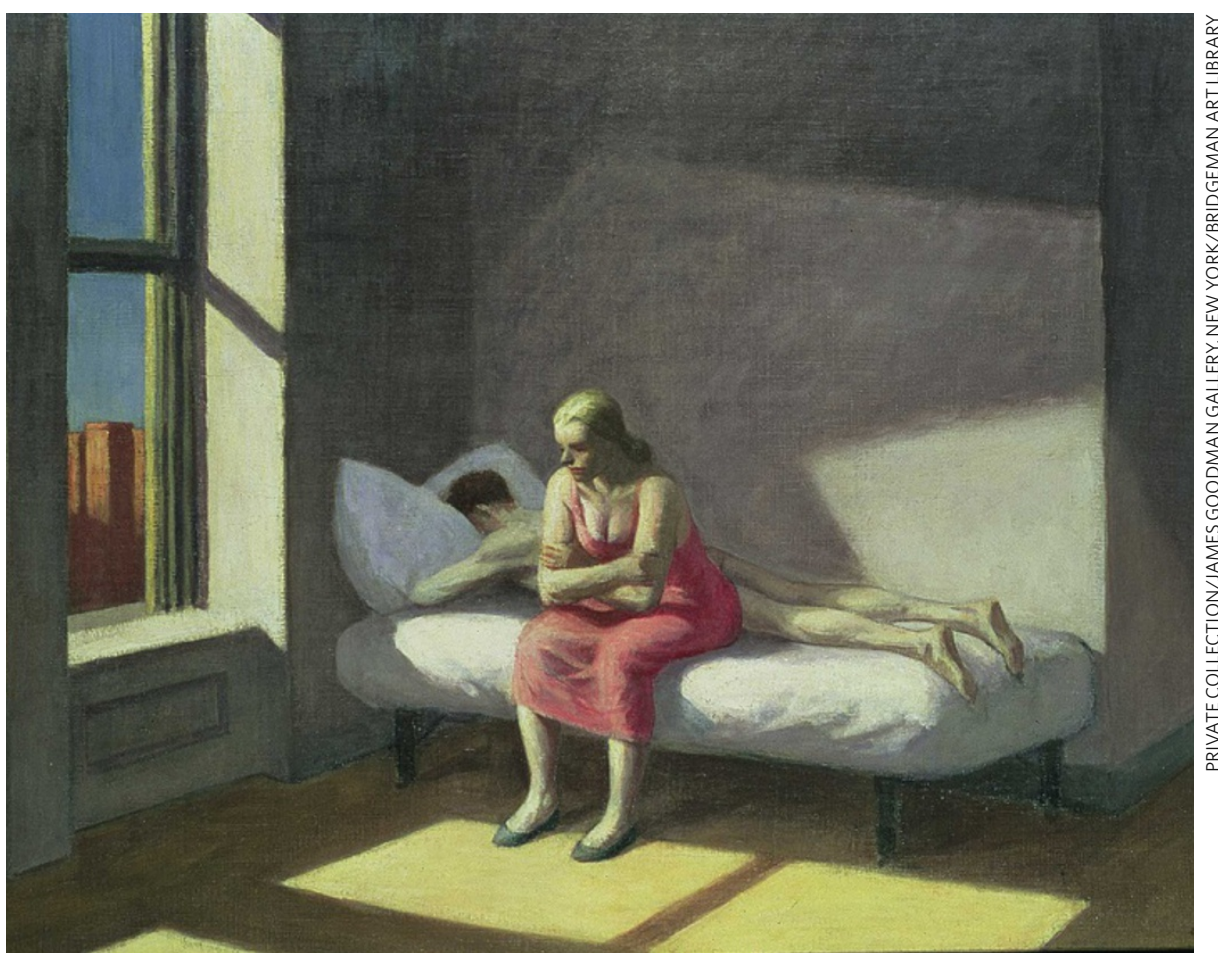

Insomnia is one of the few disorders that a general practitioner will allow a patient to self-diagnose. 
may be obvious physical causes, such as pain and physical illness, for most other sufferers (especially Green) insomnia is more a problem of wakefulness intruding into sleep, rather than just bad sleep. To be more explicit, it is a 24-hour disorder in which persistent anxiety, anger or miserable notions, sitting constantly at the back of a person's mind, ruin the expectations of their next sleep. Clearly, the eventual cure must address this state of waking mind. It is pointless going to bed with these stresses.

Despite the author's fears, insomnia by itself in an otherwise healthy person is unlikely to cause depression or mental illness, unless these are quietly developing for other reasons. Most sufferers also sleep for longer than they realize, and sleep-restriction therapy can actually be useful in treating severe depression.

Worsening Green's plight are the questionable exhortations that we live in a sleepless society riven with 'sleep debt'. Deprived sleepers supposedly run the risk of obesity, developing metabolic syndrome (a combination of risk factors associated with increased cardiovascular disease, liver disease and type 2 diabetes) or worse. This idea is based on old and often misquoted arguments that our grandparents got, on average, nine hours of sleep every night, so we should do the same. This number is flawed. The original research was carried out 100 years ago and focused on school children, not adults. Since the 1960s, findings from the United Kingdom have shown that the average daily sleep has remained consistent at around seven-and-aquarter hours.

Recent claims that inadequate sleep causes obesity mostly come from over-generalized laboratory and epidemiological findings. Acute sleep restriction - for example, four hours daily over six days - may produce metabolic changes, but few people can cope with so little sleep and the profound sleepiness that results. Even enduring less than five hours sleep a night for many years would result in only modest weight gain, on average about 1 kilogram per year. Insomniacs usually sleep more than this. Proving the possible corollary that one might lose weight by extending sleep would probably take years to accomplish; contrast this with the rapid effectiveness of exercise and diet.

Maybe Green should pause to be thankful about her life, her writing ability and even her sleep in her no doubt comfortable bedroom. The typical worker living a century ago would have toiled long hours and gone home to an impoverished, cold, damp and noisy abode, sharing a lumpy bed with the rest of the family, bed-bugs and fleas. Yet he probably slept quite well.

Jim Horne is professor of psychophysiology at Loughborough University, Leicestershire LE11 3TU, UK, and author of Sleepfaring: A Journey Through the Science of Sleep.

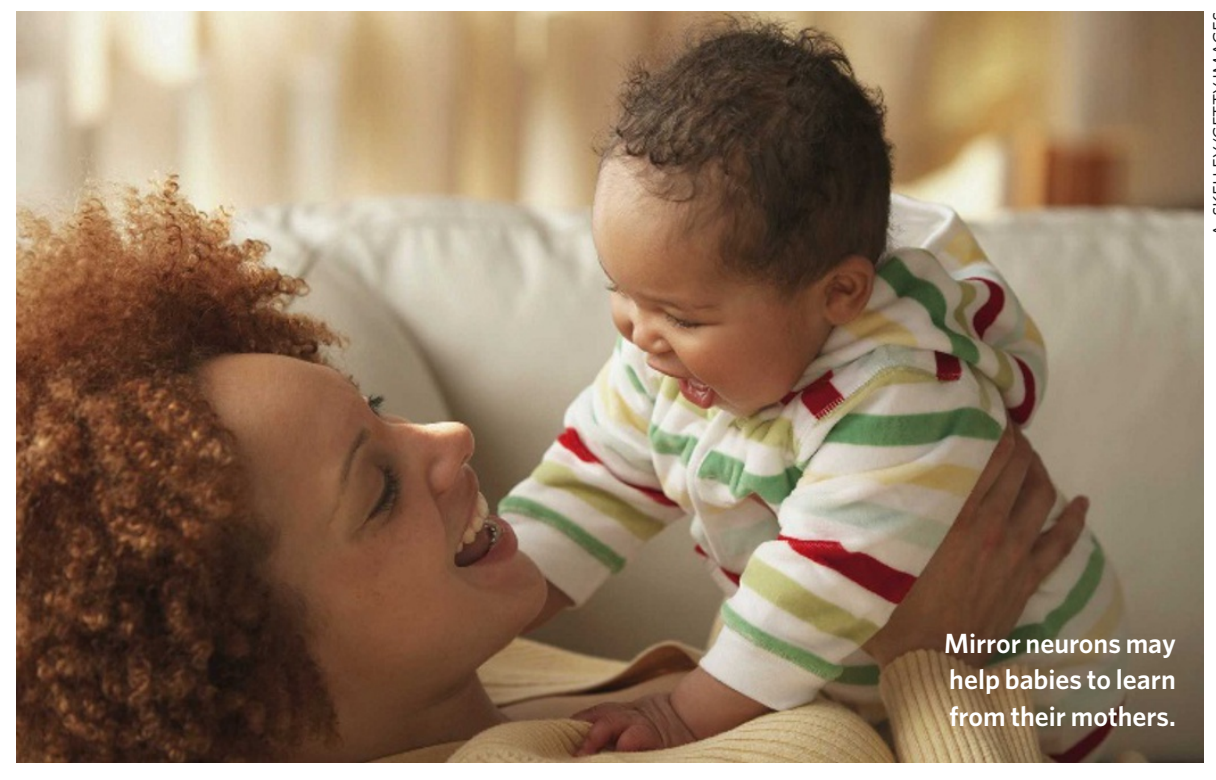

\section{Reflecting on the mind}

\section{Mirrors in the Brain}

by Giacomo Rizzolatti and Corrado

Sinigaglia. Translated by Frances

Anderson

Oxford University Press: 2007. 256 pp.

$\$ 49.95$

\section{Vilayanur S. Ramachandran}

When a paradigm-shattering discovery is made in science, it goes through three stages before gaining acceptance. First, people don't believe it; second, they claim it is of no interest; and third, they say that they have always known it. The discovery of mirror neurons in the early 1990s by Giacomo Rizzolatti, Vittorio Gallese, Marco Iacoboni and others, has been through all three stages. Happily, the idea seems to have emerged unscathed, judging from Mirrors in the Brain.

In their readable new book, Rizzolatti and philosopher of science Corrado Sinigaglia survey the growing field that the research has spawned, setting it in historical context. They begin with an overview of the neural circuits in the brain that are involved in simple goaldirected movements. When a monkey reaches for a fruit or puts something in its mouth, motor-command neurons in area F5 in the frontal lobes fire. Different neurons fire for different actions.

Rizzolatti discovered that some of these motor-command neurons fire even when a monkey just watches another monkey performing the same action. He called these cells mirror neurons. They allow one monkey to simulate or imagine another monkey's impending action. Mirror neurons have also been found that fire when a monkey watches another monkey being touched. Another class, canonical neurons, fire both when orchestrating the precise hand and finger movements required to grab a specific object and when one simply looks at that object. It is as if mere readiness to engage in a cylindrical grasp is synonymous - in terms of neural activity - with the perception of a cylinder.

Monitoring mirror-neuron activity might allow us to decipher the computations that lie at the elusive interface between perception and action, providing a key to understanding human cognition. If you extend the definition of action to include more abstract behavioural propensities, you could speak of the cells as representing 'meaning. For example, an apple can conjure many ideas that neural activity may represent differently: it can be reached for and eaten, be used to tempt Eve, can keep the doctor away, go into a pie and so on.

Mirror neurons may be involved in seemingly unrelated mental abilities, such as pretend play in children, imitating skilled actions, emotional empathy and constructing a useful model of another's actions to predict his or her intentions. Because these abilities are lost in autism, it has been suggested that the condition may result partly from mirror-neuron deficiency.

If a mirror neuron fires when someone touches you and when you watch someone being touched, how do you know the difference? One possibility is that when you watch someone else being touched, tactile receptors in your skin inform the regular, non-mirror neuron cells in your brain that they are not being touched, which inhibits the output of your mirror neurons. This would explain our observation that people who have had a hand amputated experience touch sensations in their phantom hand when watching another person's intact hand being touched. The absence of signals from the missing hand removes the inhibition, causing the patient to literally experience another person's sensations, dissolving the barrier between self and others. I have dubbed the cells involved here 'Gandhi neurons'. But the 